\title{
HYDRATION STRUCTURE OF Ti(III) AND Cr(III): MONTE CARLO SIMULATION INCLUDING THREE-BODY CORRECTIONS
}

\author{
Ahmed M. Mohammed* \\ Department of Chemistry, Addis Ababa University, P.O. Box. 1176, Addis Ababa, Ethiopia
}

(Received December 22, 2002; revised March 26, 2003)

\begin{abstract}
Classical Monte Carlo simulations were performed to investigate the solvation structures of Ti(III) and Cr(III) ions in water with only ion-water pair interaction potential and by including three-body correction terms. The hydration structures were evaluated in terms of radial distribution functions, coordination numbers and angular distributions. The structural parameters obtained by including three-body correction terms are in good agreement with experimental values proving that many-body effects play a crucial role in the description of the hydration structure of highly charged ions.
\end{abstract}

KEY WORDS: Monte Carlo simulations, Hydration structures of $\mathrm{Ti}(\mathrm{III})$ and $\mathrm{Cr}(\mathrm{III})$ ions, Threebody corrections

\section{INTRODUCTION}

Classical Monte Carlo (MC) simulation techniques have been used widely for the study of solvating structure of metal ions [1-5]. However, the types of metal under study and ion-solvent interaction potentials used have affected their degree of success. In some monovalent and divalent metal ions with only pairwise additive intermolecular potentials, structural results that are in good agreement with those obtained experimentally have been achieved [3, 6-9].

Nevertheless, in most cases, with divalent and trivalent metals, the inclusion of many body interactions has been to be crucial $[2,4,5,10]$. The failure of pairwise additivity for cationwater potentials, particularly for divalent and trivalent ions, has been handled in various ways. One approach that has been used is the nearest-neighbor ligand correction (NNLC) [11, 12] algorithm, which uses in addition to pair potential terms a three-body correction term based on ab initio calculation of the molecular interaction energy surface of the metal ion monohydrate with another water molecule. However, the most successful and exact approach is to supplement the potential energy function to be employed by many-body terms. In many cases, three-body potentials calculated by ab initio methods have reproduced properly hydration numbers $[2,4,5]$.

According to experimental investigations, $\mathrm{Cr}^{3+}$ ion is very stable in solution [1], where as $\mathrm{Ti}^{3+}$ easily oxidizes and its structure could be verified, therefore, only in the solid state $[13,14]$. Tahikawa [15] et al. have carried out electron spin resonance (ESR), electron nuclear double resonance (ENDOR) and electron spin-echo studies to determine the hydration structure of $\mathrm{Ti}^{3+}$ ion in the amorphous solid of a 2-propanol/ $\mathrm{D}_{2} \mathrm{O}$ mixture, that six water molecules coordinate to the central metal ion with an average $\mathrm{Ti}^{3+}-\mathrm{O}$ distance of $2.2 \AA$. The hexaquo $\mathrm{Ti}^{3+}$ ion persists in the solid state structure of $\mathrm{TiCl}_{3} \cdot 6 \mathrm{H}_{2} \mathrm{O}$ [16] and the cesium alum $\mathrm{CsTi}\left(\mathrm{SO}_{4}\right)_{2} \cdot 12 \mathrm{H}_{2} \mathrm{O}$ [17], in which the $\mathrm{Ti}(\mathrm{III})-\mathrm{O}$ distance is quoted as $2.03 \AA$. The $\mathrm{X}$-ray crystal structure of the pts $\left(\mathrm{C}_{7} \mathrm{H}_{7} \mathrm{O}_{3} \mathrm{~S}^{-}\right)$salt $\left[\mathrm{Ti}\left(\mathrm{OH}_{2}\right)_{6}\right](\mathrm{pts})_{3} \cdot 3 \mathrm{H}_{2} \mathrm{O}$ has also been reported [18]. Here the geometry around $\mathrm{Ti}(\mathrm{III})$ was found to be essentially octahedral with Ti(III)-O bond lengths ranging from 2.018(5) to $2.046(6) \AA$.

*Corresponding author. E-mail: am_mohammed@yahoo.com 
The hydration of $\mathrm{Cr}(\mathrm{III})$ has been the focus of many experimental [1, 19-29] and theoretical [1, 30-34] investigations and the ion was reported to have a kinetically extremely inert first coordination shell with six octahedrally coordinated water molecules, using X-ray (XD) $[1,18$ 20], neutron diffraction (ND) [1, 23, 24], LAXS [26, 27], and EXAFS methods [1, 26-29]. The fact that it possesses a very stable first hydration shell has also given a good opportunity to study the second hydration shell [25-34].

In this work, MC simulations with and without 3-body corrections for one M(III) in 499 water molecules were carried out. The structural data of the hydrated M(III) ions are discussed in terms of $\mathrm{M}(\mathrm{III})-\mathrm{O}$ and $\mathrm{M}(\mathrm{III})-\mathrm{H}$ radial distribution functions (RDFs), coordination number and angular distributions.

\section{DETAILS OF CALCULATIONS}

In this study, ion-water $\left(\mathrm{M}(\mathrm{III})-\mathrm{H}_{2} \mathrm{O}, \mathrm{M}=\mathrm{Cr}, \mathrm{Ti}\right)$ pair interaction potentials and three-body corrections $\left(\mathrm{H}_{2} \mathrm{O}-\mathrm{M}(\mathrm{III})-\mathrm{H}_{2} \mathrm{O}\right)$ are taken from reference 35 , the form of the two and three-body potentials together with their parameters are displayed in Table 1. For water-water interactions, the CF2 potential [36] was used, as this model is more consistent than the MCY [37] model for the type of ion-water pair potentials used [38] and in contrast to rigid models [39] (TIP3P, TIP4P and TIP5P) allows an adaptation of $\mathrm{HOH}$ angle and $\mathrm{OH}$ bond length in the ligand molecules upon complexing the metal ion.

Table 1. Two- and three-body potentials and their parameters for $\mathrm{M}(\mathrm{III})$-water $(\mathrm{M}=\mathrm{Ti}$ and $\mathrm{Cr})$ interactions.

\begin{tabular}{|c|c|c|c|c|c|c|}
\hline \multicolumn{7}{|c|}{ 2-body } \\
\hline \multicolumn{7}{|c|}{$E_{2 b d}=\sum_{i}\left(\frac{q_{i} q_{M}}{r_{i M}}+A_{i M} r_{i M}^{-A}+B_{i M} r_{i M}^{-B}+C_{i M} r_{i M}^{-C}+D_{i M} r_{i M}{ }^{-D}\right)$} \\
\hline $\mathrm{M}(\mathrm{III})$ & Atom & $\mathrm{A}(\mathrm{kcal} / \mathrm{mol})^{-\mathrm{A}}$ & $\mathrm{B}(\mathrm{kcal} / \mathrm{mol})^{-\mathrm{B}}$ & $\mathrm{C}(\mathrm{kcal} / \mathrm{mol})^{-\mathrm{C}}$ & $\mathrm{D}(\mathrm{kcal} / \mathrm{mol})^{-\mathrm{D}}$ & A,B,C,D \\
\hline \multirow[t]{2}{*}{$\mathrm{Ti}$} & $\mathrm{O}$ & -6998.67 & 27955.45 & -29711.35 & 11460.98 & $4,6,9,12$ \\
\hline & $\mathrm{H}$ & 2106.39 & -6501.74 & 5764.12 & - & $4,6,12$ \\
\hline \multirow[t]{2}{*}{$\mathrm{Cr}$} & $\mathrm{O}$ & -7657.01 & 97017.22 & -110764.54 & 17811.97 & $5,8,9,12$ \\
\hline & $\mathrm{H}$ & 198.34 & -957.47 & 869.28 & - & $5,8,12$ \\
\hline \multicolumn{7}{|c|}{ 3-body } \\
\hline \multicolumn{7}{|c|}{$E_{3 b d}=\left(A_{1} \exp \left(-A_{2}\left({r_{M O_{1}}}^{2}+{r_{M O_{2}}}^{2}\right)\right) \exp \left(-A_{3}\left(r_{O_{1} O_{2}}\right)\right)^{2}-\frac{A_{4}}{r_{M O_{1}}}-\frac{A_{4}}{r_{M O_{2}}}\right.$} \\
\hline \multicolumn{2}{|c|}{$\mathrm{H}_{2} \mathrm{O}-\mathrm{M}(\mathrm{III})-\mathrm{H}_{2} \mathrm{O}$} & $A_{l}$ & & $A_{2}$ & & $A_{3}$ \\
\hline \multicolumn{2}{|c|}{$\mathrm{Ti}$} & 0.0639941 & & -0.2179486 & & 0.3053575 \\
\hline \multicolumn{2}{|c|}{$\mathrm{Cr}$} & 0.8727987 & & 0.2593399 & & 0.5041385 \\
\hline
\end{tabular}

Charges on $\mathrm{O}$ and $\mathrm{H}$, taken from the $\mathrm{CF}^{36}$ water-water interaction potential, are -0.6598 and 0.3299 , respectively. $\mathrm{M}$ refers to metal ion. $\mathrm{i}$ in the 2-body potential function refers to oxygen or hydrogen. $\mathrm{O}_{\mathrm{i}}$ and $\mathrm{CL}$ in the 3-body potential function refer to the oxygens of the water molecules and cut off limit $(6 \AA)$, respectively. 
MC simulations with pair potential

The MC simulations were carried out in the canonical ensemble using the Metropolis [40] algorithm for a system consisting of one M(III) ion and 499 water molecules in a periodic cube at the temperature $298.16 \mathrm{~K}$. A spherical cut off at half of the box length $(12.345 \AA)$ was introduced. The density of $0.997 \mathrm{~g} \mathrm{~cm}^{-3}$ was assumed to be the same as that of pure water. After generating a starting configuration randomly, the system reached energetic equilibrium after 3 million configurations. For evaluation of structural data, especially the radial distribution functions (RDFs), a further 3 million configurations were sampled.

\section{MC simulations including three-body corrections}

Under the same conditions as in the previous section MC simulations including three-body correction terms were carried out for one M(III) and 499 water molecules, water-water interactions being treated again by the $\mathrm{CF} 2$ potential. Within the cut off limit of $6.0 \AA$, the three body correction function was applied, as at large M(III)-water distances these terms could be regarded to vanish according to the ab initio results. After randomly generating an initial configuration, the systems reached equilibrium after 3 million configurations. To evaluate radial distribution functions and other structural data, another 3 million configurations were sampled.

\section{RESULTS AND DISCUSSION}

\section{Structural data}

Pair potential simulations

The results obtained from simulations with only pair potential are far from the realistic values (Figures 1-6). The average first hydration shell coordination numbers are overestimated, 9 for Ti(III) and 8 for $\mathrm{Cr}$ (III) ion. The M(III)-O RDFs show small additional peaks which have been shown to be an artifact of simulations with only pair potentials [41, 42]. The angular distributions obtained show unusual ligand orientations due to the presence of 9 and 8 water molecules in the first hydration shells of $\mathrm{Ti}(\mathrm{III})$ and $\mathrm{Cr}$ (III) ion, respectively. Therefore, it is obvious from these results that simulations based on ab initio pair potentials, as expected, are inadequate to determine coordination numbers and thus even a rough structure of hydrated trivalent ions, and that at least 3-body correction is mandatory to correctly describe the hydration of these ions.

Three-body corrected simulations

\section{$\mathrm{Ti}(\mathrm{III})-\mathrm{H}_{2} \mathrm{O}$}

The Ti(III)-O and Ti(III)-H RDFs including three-body effects are shown in Figure 7. In the Ti(III)-O RDF there are three peaks. The small artificial peak obtained in the pair potential simulation has disappeared. The first peak, which corresponds to the first hydration shell in the Ti(III)-O RDFs is centered at $2.10 \AA$ and the second peak at $4.68 \AA$. This implies that the first hydration shell is well separated from the second hydration shell. A third peak centered at 5.86 $\AA$ is observed. This splitting of the second shell has also been observed in the case of $\mathrm{Fe}^{3+}$ [35]. It seems to be a phenomenon associated with these types of ions. 


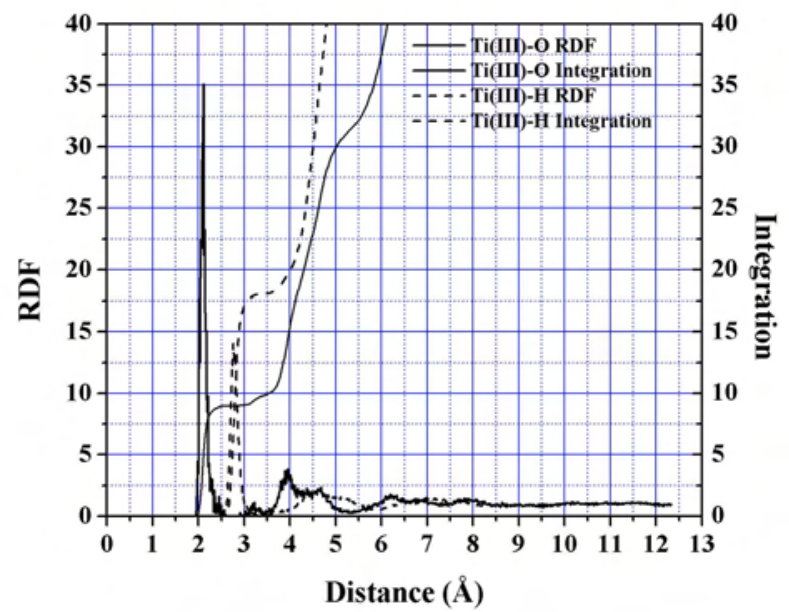

Figure 1. Ti(III)-O and $\mathrm{Ti}(\mathrm{III})-\mathrm{H}$ radial distribution functions and their running integration number simulations with only pair potential.

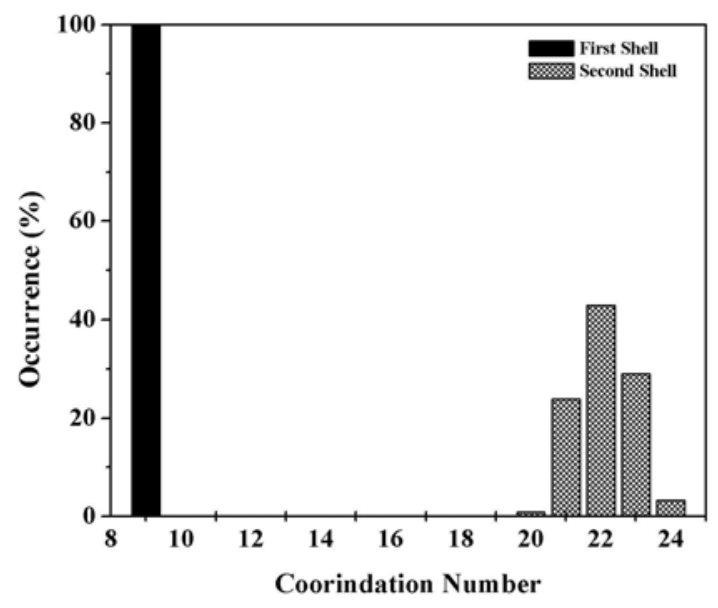

Figure 2. First and second-shell coordination number distribution of hydrated Ti(III) simulations with only pair potential. 


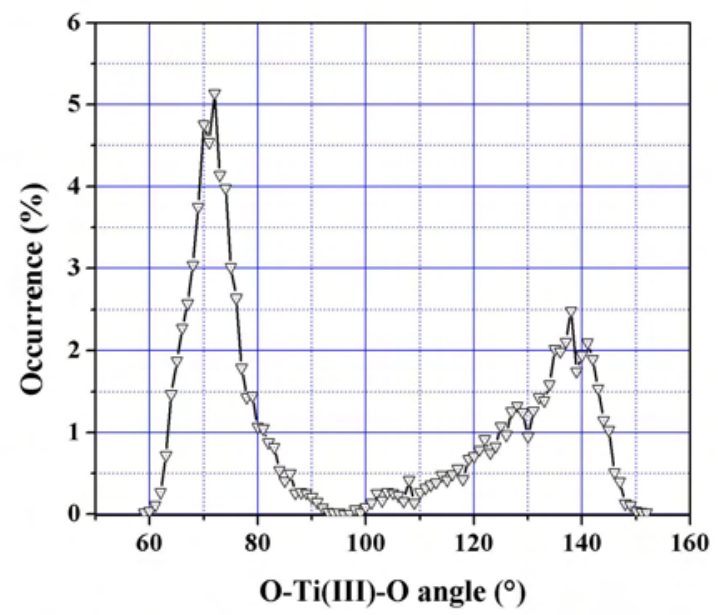

Figure 3. Distribution of the bond angles $\mathrm{H}_{2} \mathrm{O}-\mathrm{Ti}(\mathrm{III})-\mathrm{H}_{2} \mathrm{O}$ simulations with only pair potential.

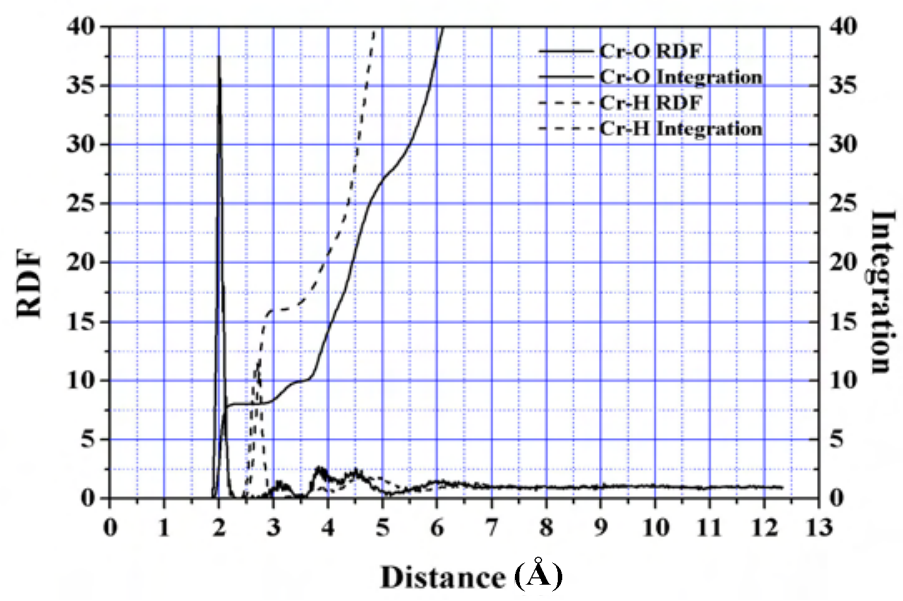

Figure 4. $\mathrm{Cr}$ (III)-O and $\mathrm{Cr}$ (III)-H radial distribution functions and their running integration number simulations with only pair potential. 


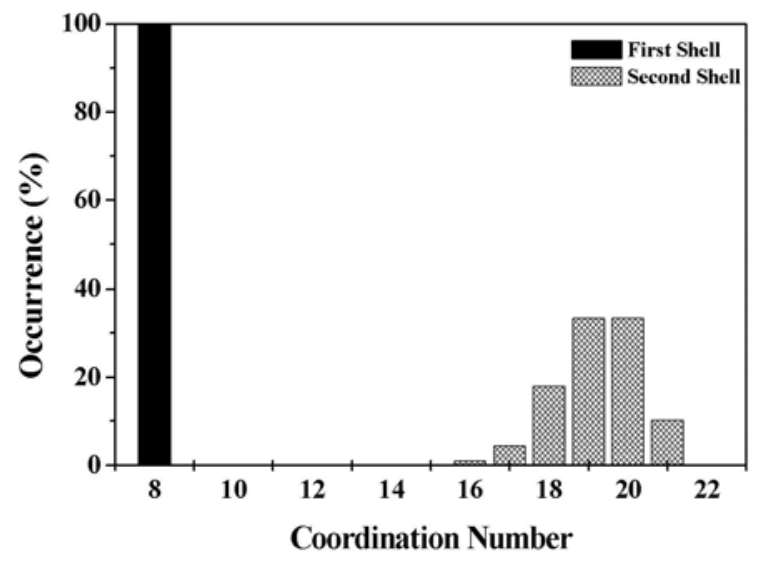

Figure 5. First and second-shell coordination number distribution of hydrated $\mathrm{Cr}(\mathrm{III})$ simulations with only pair potential.

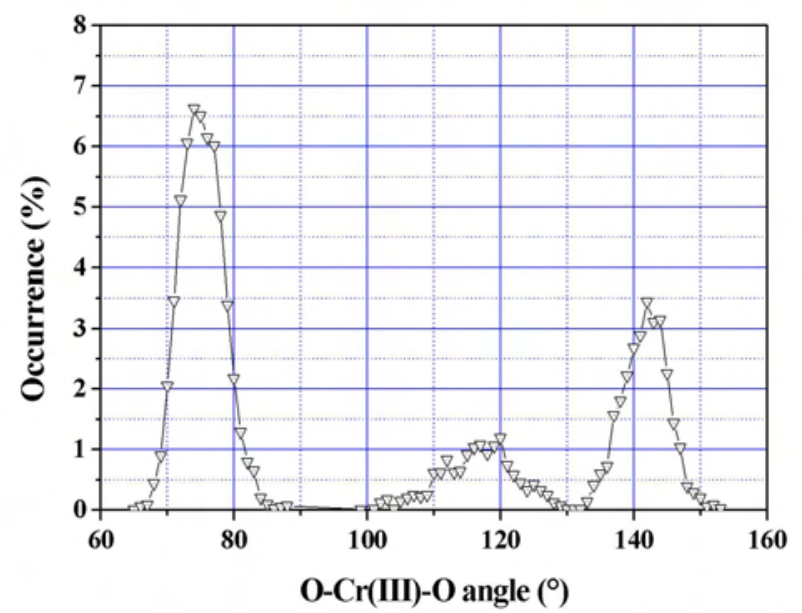

Figure 6. Distribution of the bond angles $\mathrm{H}_{2} \mathrm{O}-\mathrm{Cr}(\mathrm{III})-\mathrm{H}_{2} \mathrm{O}$ simulations with only pair potential. 


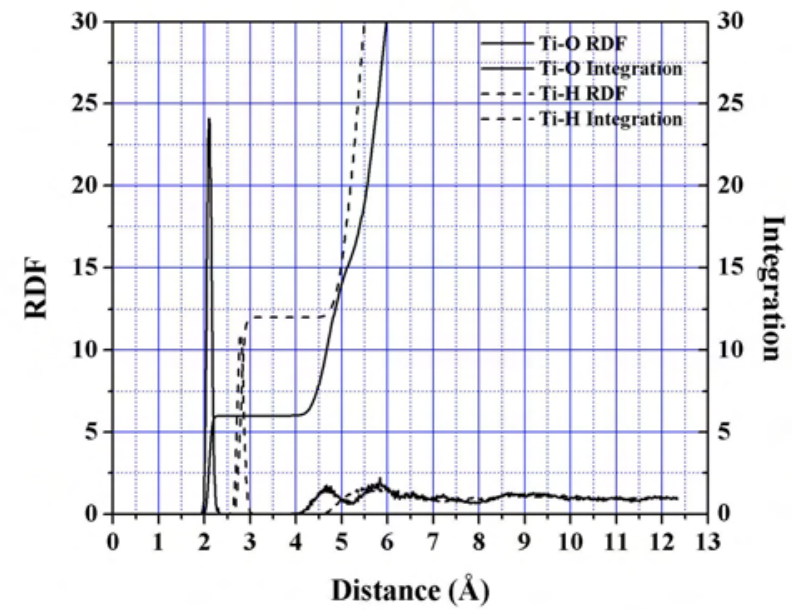

Figure 7. Ti(III)-O and $\mathrm{Ti}(\mathrm{III})-\mathrm{H}$ radial distribution functions and their running integration number simulations including three-body correction.

The Ti(III)-H RDFs show only two peaks, the first peak centered at $2.80 \AA$. The shift of the $\mathrm{Ti}(\mathrm{III})-\mathrm{H}$ RDFs to larger distances with respect to the corresponding oxygen RDF indicates that especially in the first shell, the water molecules are well oriented to obey the dominant ion-water interactions with their oxygen atoms pointing to the ion. Some characteristic values for $\mathrm{Ti}(\mathrm{III})-\mathrm{O}$ and $\mathrm{Ti}(\mathrm{III})-\mathrm{H}$ radial distribution functions are listed in Table 2. Since the simulation performed does not include higher than three-body effects it can not account for the Jahn-Teller effect [43] which is expected to occur in $\left[\mathrm{Ti}\left(\mathrm{H}_{2} \mathrm{O}\right)_{6}\right]^{3+}$ but the $\mathrm{Ti}(\mathrm{III})-\mathrm{O}$ distance appears to be a reasonable average of the results obtained in the solid state $(2.03 \AA)$ [16-18] and that obtained for the aqueous solution on amorphous solid of a 2-propanol/ $\mathrm{D}_{2} \mathrm{O}$ mixture by Tachikawa $(2.20 \AA)$ [15].

Table 2. Characteristic values of the radial distribution functions, $\left.g_{\alpha \beta} r\right)$, for the Ti(III) in water determined by molecular simulation methods.

\begin{tabular}{|c|c|c|c|c|}
\hline$\alpha-\beta$ & $r_{1}{ }^{\mathrm{a}}$ & $n_{1}{ }^{\mathrm{b}}$ & $r_{2}{ }^{\mathrm{a}}$ & $n_{2}{ }^{\mathrm{b}}$ \\
\hline Ti-O & 2.10 & 6.0 & 4.68 & 12 \\
\hline Ti-H & 2.80 & 12.0 & 5.35 & 46 \\
\hline
\end{tabular}

${ }^{\mathrm{a}} r_{\mathrm{i}}$ is the distances in $\AA$ of the $i^{\text {th }}$ maximum. ${ }^{\mathrm{b}} n_{\mathrm{i}}$ is the average coordination number obtained by integration of RDF for the $i^{\text {th }}$ coordination shell.

The most significant improvement over pair potential result is the change of the first hydration shell coordination to 6 (Figure 8). The mean coordination numbers for the second hydration shell are 12 implying that every first shell water molecule interacts with 2 water molecules in the second shell. This shows that ligand orientation and binding is almost entirely determined by hydrogen bonding. 
The hydration shell structure of $\mathrm{Ti}(\mathrm{III})$ is further illustrated on the basis of O-Ti(III)-O angular distribution function (Figure 9). The angular distribution displays only two peaks centered at $90^{\circ}$ and $175^{\circ}$, corresponding to a slightly distorted octahedral complex.

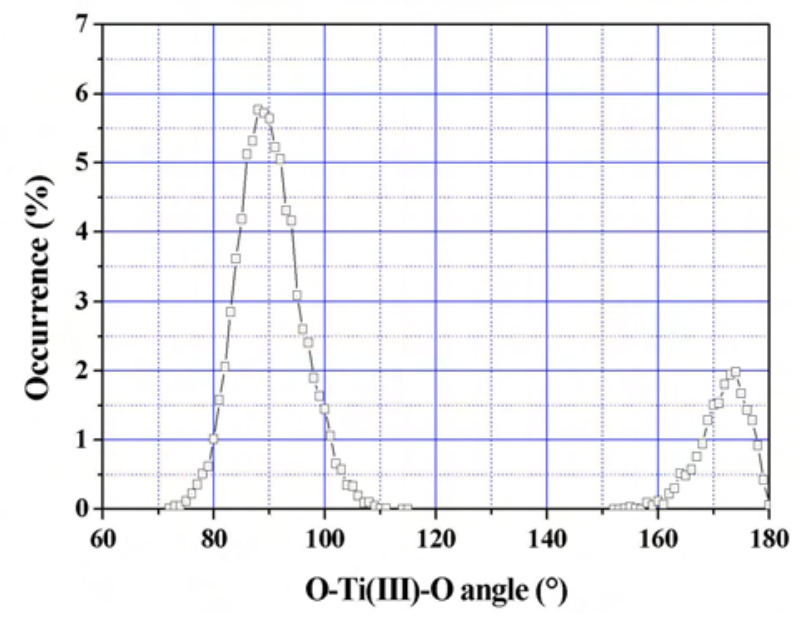

Figure 8. First and second-shell coordination number distribution of hydrated Ti(III) simulations including three-body correction.

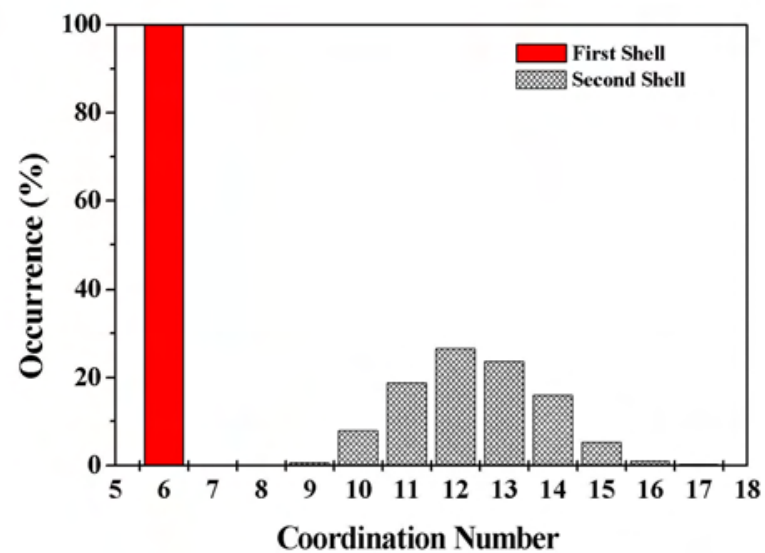

Figure 9. Distribution of the bond angles $\mathrm{H}_{2} \mathrm{O}-\mathrm{Ti}(\mathrm{III})-\mathrm{H}_{2} \mathrm{O}$ simulations including three-body correction. 
$\mathrm{Cr}(\mathrm{III}))-\mathrm{H}_{2} \mathrm{O}$

The resulting RDFs for $\mathrm{Cr}(\mathrm{III})-\mathrm{O}$ and $\mathrm{Cr}(\mathrm{III})-\mathrm{H}$ including 3-body correction term are plotted in Figure 10. In the $\mathrm{Cr}(\mathrm{III})-\mathrm{O}$ RDF, the first hydration shell is represented by a sharp peak centered at $2.02 \AA$. The $\mathrm{Cr}(\mathrm{III})-\mathrm{O}$ RDF further shows the presence of a well-defined second hydration shell centered at $4.33 \AA$, followed by a broad peak between $6-7 \AA$, which could be ascribed to a diffuse third hydration shell and it reflects mainly the strong ordering effect induced on the solvent by the $\mathrm{Cr}(\mathrm{III})$ ion. The $\mathrm{Cr}(\mathrm{III})-\mathrm{O}$ RDF becomes zero after the first peak and remain almost zero for more than $1 \AA$ suggesting that the first hydration shell is very stable and that ligand exchange with the second shell must be rather marginal, in agreement with experimental results $\left.\left\{k(298)=2.4 \times 10^{-6}\right)\right\}[44]$.

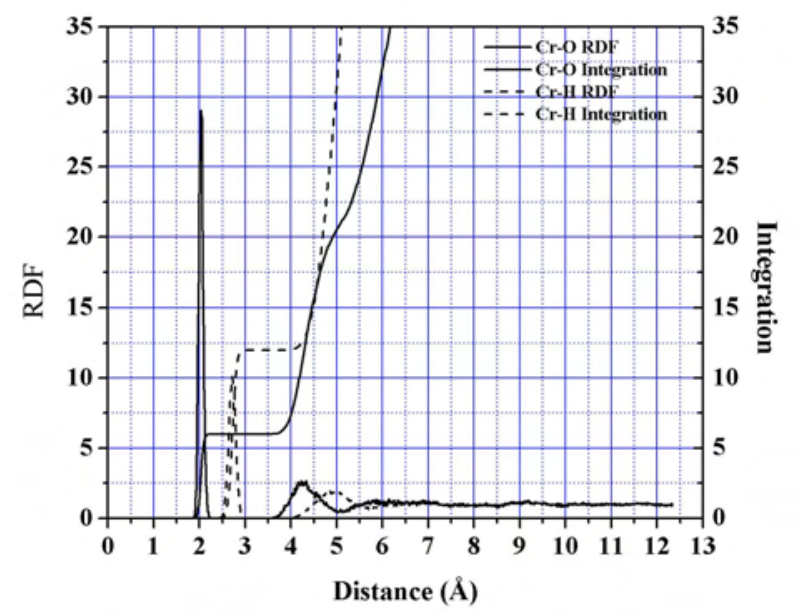

Figure 10. $\mathrm{Cr}$ (III)-O and $\mathrm{Cr}$ (III)-H radial distribution functions and their running integration number simulations including three-body correction.

The Cr(III)-H RDF confirms the presence of first and second hydration shells and are centered at $2.71 \AA$ and $4.84 \AA$, respectively. The larger distances $(0.7 \AA)$ of the $\mathrm{Cr}$ (III)-H RDF with respect to the corresponding $\mathrm{Cr}(\mathrm{III})-\mathrm{O}$ RDF peak indicates that especially in the first shell, the water molecules are well oriented to point with the dipoles to the ion and that the first shell has rather a rigid structure. Some characteristic values obtained from the $\mathrm{Cr}(\mathrm{III})-\mathrm{O}$ and $\mathrm{Cr}(\mathrm{III})-\mathrm{H}$ RDFs are displayed and compared with experimental and simulation investigations in Table 3.

The percentage distribution of coordination number of $\mathrm{Cr}(\mathrm{III})-\mathrm{H}_{2} \mathrm{O}$ in the first and second shell as obtained from the running interaction numbers are shown in Figure 11. Again the most significant achievement in the simulation including 3-body correction is the change of the first hydration number from 8 to $6(100 \%)$. The second hydration number which is supposed to be between 13 and 14 [27] according to experimental investigations has also changed from 19 to 15 (see Table 3). This implies that every first shell water molecule interacts with about 2.5 water molecules reflecting that ligand binding and orientation are not entirely determined by hydrogen bonding. 
Table 3. Comparison of hydration structure parameters for $\mathrm{Cr}(\mathrm{III})$.

\begin{tabular}{|c|c|c|c|c|c|c|c|c|}
\hline Solution & $\alpha-\beta$ & $\mathrm{N}^{\mathrm{a}} /$ conc. & $r_{1}{ }^{\mathrm{b}}$ & $n_{\mathrm{I}}{ }^{\mathrm{c}}$ & $r_{2}{ }^{\mathrm{b}}$ & $n_{2}{ }^{\mathrm{c}}$ & Method & Ref. \\
\hline $\mathrm{Cr}\left(\mathrm{ClO}_{4}\right)_{3}$ & $\mathrm{Cr}-\mathrm{O}$ & $1 \mathrm{M}$ & $2.03 \pm 0.02$ & 6 & $4.02(2)$ & $13(1)$ & LAXS & 25 \\
\hline $\mathrm{CrCl}_{3}$ & $\mathrm{Cr}-\mathrm{O}$ & $1 \mathrm{M}$ & $1.994(3)$ & 6 & $4.05(2)$ & 12 & XRD & 17 \\
\hline $\mathrm{Cr}\left(\mathrm{NO}_{3}\right)$ & $\mathrm{Cr}-\mathrm{O}$ & $1 \mathrm{M}$ & $1.999(3)$ & 6 & $4.08(1)$ & 12 & XRD & 17 \\
& & $0.5 \mathrm{M}$ & 1.98 & 6 & $4.20-4.25$ & & XRD & 18 \\
& & $0.05 \mathrm{~m}$ & $2.00 \pm 0.01$ & $6.0 \pm 0.1$ & $3.97 \pm 0.08$ & $13.4 \pm 1.3$ & EXAFS & 25 \\
& & $0.01 \mathrm{~m}$ & $2.01 \pm 0.01$ & $6.0 \pm 0.1$ & $4.02 \pm 0.08$ & $13.4 \pm 1.3$ & EXAFS & 25 \\
& & $0.001 \mathrm{~m}$ & $2.01 \pm 0.01$ & $6.4 \pm 0.1$ & $4.00 \pm 0.08$ & $13.6 \pm 1.0$ & EXAFS & 25 \\
\hline$\left[\mathrm{Cr}\left(\mathrm{H}_{2} \mathrm{O}\right)_{6}\right]^{3+}$ & $\mathrm{Cr}-\mathrm{O}$ & 512 & & & 4.08 & $12.3 \pm 0.01$ & MC & 31 \\
\hline$\left[\mathrm{Cr}\left(\mathrm{H}_{2} \mathrm{O}\right)_{6}\right]^{3+}$ & $\mathrm{Cr}-\mathrm{O}$ & 512 & & & $4.06 \pm 0.03$ & $14 \pm 1$ & MC & 29 \\
\hline $\mathrm{Cr}(\mathrm{III})$ & $\mathrm{Cr}-\mathrm{O}$ & 499 & 2.02 & 6 & 4.33 & 15 & MC & This \\
& & & & & & & & work \\
\hline
\end{tabular}

${ }^{\text {a }}$ Number of $\mathrm{H}_{2} \mathrm{O}$ molecules in the simulation box. ${ }^{\mathrm{b}} r_{\mathrm{i}}$ is the distance in $\AA$ of the $i^{\text {th }}$ maximum of the RDF.

${ }^{\mathrm{c}} n_{\mathrm{i}}$ is the average hydration number integrated up $r_{\mathrm{mi}}$ of the $i^{\text {th }}$ shell.

In Figure 12, the $\mathrm{O}-\mathrm{Cr}(\mathrm{III})-\mathrm{O}$ angular distribution calculated up to the first minimum of the $\mathrm{Cr}(\mathrm{III})-\mathrm{O}$ RDF is shown. The angular distribution shows two peaks with maximum values at $90^{\circ}$ and $172^{\circ}$, suggesting an octahedral geometry.

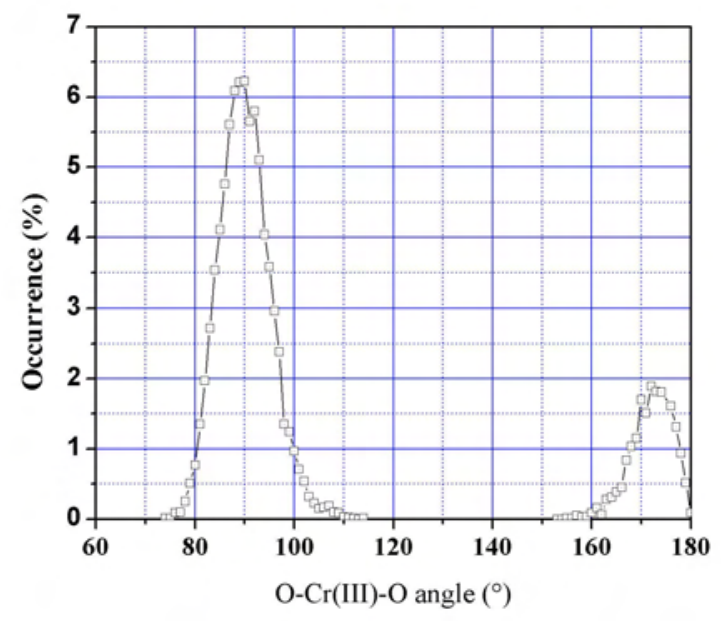

Figure 11. First and second-shell coordination number distribution of hydrated $\mathrm{Cr}$ (III) simulations including three-body correction. 


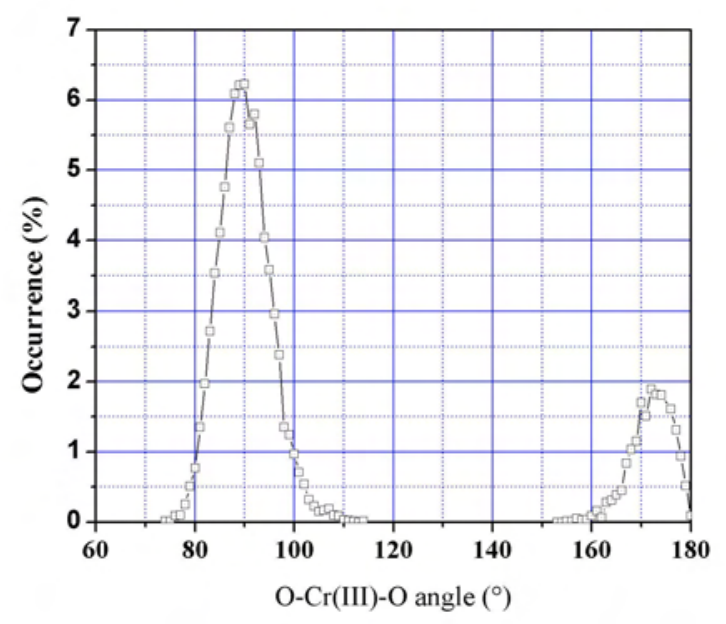

Figure 12. Distribution of the bond angles $\mathrm{H}_{2} \mathrm{O}-\mathrm{Cr}(\mathrm{III})-\mathrm{H}_{2} \mathrm{O}$ simulations including three-body correction.

\section{CONCLUSION}

The ab initio two-body potentials are inadequate to describe the hydration structure of Ti(III) and $\mathrm{Cr}(\mathrm{III})$ ions. The inclusion of 3-body effects reduces the average first shell coordination numbers from 9 and 8 (pair potential values) to 6 for both Ti(III) and $\mathrm{Cr}$ (III). The results of this study, therefore, suggest that any successful simulation of triply charged transition metal cations in aqueous solution, must include at least 3-body effect to give correct structural parameters.

It seems desirable to include in further studies higher n-body effects as needed to account for the Jahn-Teller effect which is expected to occur in $\left[\mathrm{Ti}\left(\mathrm{H}_{2} \mathrm{O}\right)_{6}\right]^{3+}$ and has been observed in a QM/MM-MC simulation of hydrated $\mathrm{Cu}$ (II) [45].

\section{REFERENCES}

1. Ohtaki, H.; Radnai, T. Chem. Rev. 1993, 93, 1157.

2. Pranowo, H.D.; Rode, B.M. J. Phys. Chem. A 1999, 103, 4298.

3. Pranowo, H.D.; Bambang Setiaji, A.H.; Rode, B.M. J. Phys. Chem. A 1999, 103, 11115.

4. Marini, G.W.; Texler, N.R.; Rode, B.M. J. Phys. Chem. 1996, 100, 6808.

5. Texler, N.R.; Rode, B.M. J. Chem. Phys. 1995, 99, 15714.

6. Limtrakul, J.P.; Probst, M.M.; Rode, B.M. J. Mol. Struct. (THEOCHEM) 1985, 23, 121.

7. Bopp, P.; Okada, I.; Ohtaki, H.; Henizinger, K. Z. Naturforsch., Teil A 1985, 40, 116.

8. Spohr, E.; Pálinkás, G.; Heinzinger, K.; Bopp, P.; Probst, M. M. J. Phys. Chem. 1988, 92, 6754.

9. Curtiss, L.A.; Jurgens, R. J. Phys. Chem. 1990, 94, 5509.

10. Cordeiro, M.N.D.S.; Gomes, J.A.N.F.; González-Lafont, A.; Lluch, J.M.; Bertrán, J. Chem. Phys. 1990, 141, 379. 
11. Rode, B.M.; Islam, S.M. Z. Naturforsch., Teil A 1991, 46, 357.

12. Yongyai, Y.; Kokpol, S.; Rode, B.M. Chem. Phys. 1991, 156, 403.

13. Beattie, J.K.; Best, S.P.; Skelton, B.W; White, A.H. J. Chem. Soc., Dalton Trans. 1981, 2105.

14. Best, S.P.; Forsyth, J.B.; Tregenna-Piggott, P.L. J. Chem. Soc., Dalton Trans. 1993, 2711.

15. Tachikawa, H.; Ichikawa, T.; Yoshida, H. J. Am. Chem. Soc. 1990, 112, 977.

16. Furman, S.C.; Garner, C.S. J. Am. Chem. Soc. 1951, 73, 4528.

17. Lipson, H. Proc. Roy. Soc. London A 1935, 151, 347.

18. Hartmann, H.; Schlafer, H.L. Z. Naturforsh., A 1951, 6, 754.

19. Aquino, M.A.S.; Clegg, W.; Liu, Q.T.; Sykes, A.G. Acta Cryst. 1995, C51, 560.

20. Camaniti, R.; Licheri, G.; Piccagula, G.; Pinna, G. J. Chem. Phys. 1978, 69, 1.

21. Bol, W.O.; Welzen, T. Chem. Phys. Lett. 1977, 49, 189.

22. Magini, M. J. Chem. Phys. 1980, 73, 2499.

23. Broadbent, R.D.; Neislon, G.W.; Sandstörm, M. J. Phys.: Condens. Matter 1992, 4, 639.

24. Johansson, G. Adv. Inorg. Chem. 1992, 39, 159.

25. Read, M.C.; Sandström, M. Acta Chem. Scand. 1992, 46, 1177.

26. Lindqvist-Reis, P.; Muñoz-Páez, A.; Diáz-Moreno, S.; Pattanailk, S.; Persson I.; Sandström, M. Inorg. Chem. 1998, 37, 6675.

27. Muñoz-Páez, A.; Pappalardo, R.R.; Sánchez Markos, E. J. Am. Chem. Soc. 1995, 117, 11710.

28. Sakane, H.; Muñoz-Páez, A.; Diáz-Moreno, S.; Martínez, J.M.; Pappalardo, R.R.; Sánchez Markos, E. J. Am. Chem. Soc. 1998, 120, 10401.

29. Bieuzen, A.; Foglia, F.; Furet, E.; Helm, L.; Merbach, A.E.; Weber, J. J. Am. Chem. Soc. 1996, 118, 12777.

30. Pappalardo, R.R.; Sánchez Markos, E. J. Chem. Phys. 1993, 97, 4500.

31. Sánchez Markos, E.; Pappalardo, R.R.; Martínez, J.M. J. Phys. Chem. 1996, 100, 11748.

32. Floris, F.; Persico, M.; Tani, A.; Tomasi, J. Chem. Phys. 1995, 195, 207.

33. Martínez, J.M.; Hernández-Cobos, J.; Saint-Martin, H.; Pappalardo, R.R.; Sánchez Marcos, E. J. Chem. Phys. 2000, 112, 2339.

34. Martínez, J.M.; Pappalardo, R.R.; Sánchez Marcos, E. J. Chem. Phys. 1998, 109, 1445.

35. Mohammed, A.M. Ph.D. Dissertation, University of Innsbruck, Austria, 2001.

36. Jancsó, G.; Heinzinger, K.; Bopp. P. Z. Naturforsch., A 1985, 40, 1235.

37. Matsuoka, O.; Clementi, E.; Yoshimine, M. J. Phys. Chem. 1976, 79, 1351.

38. Rode, B.M. J. Phys. Chem. 1992, 96, 4170.

39. Mahoney, M.W.; Jorgensen, W.L. J. Chem. Phys. 2000, 112, 8910.

40. Metropolis, N.; Rosenbluth, A.W.; Teller, A.H.; Teller, E. J. Chem. Phys. 1953, 21, 1087.

41. Hannongbua, S. J. Chem. Phys. 1997, 106, 6076.

42. Hannongbua, S.; Rode, B.M. Chem. Phys. 1992, 162, 257.

43. Jahn, H.A.; Teller, E. Proc. Roy. Soc. London A 1937, 161, 220.

44. Helm, L.; Merbach, A.E. Coord. Chem. Rev. 1999, 187, 151.

45. Marini, G.W.; Liedl, K.R.; Rode, B.M. J. Phys. Chem. A 1999, 103, 11387. 